\title{
Hoodia gordonii: An Up-to-Date Review of a Commercially Important Anti-Obesity Plant
}

Authors

Affiliation
Ilze Vermaak, Josias H. Hamman, Alvaro M. Viljoen

Department of Pharmaceutical Sciences, Faculty of Science, Tshwane University of Technology, Pretoria, South Africa
Key words

- Hoodia gordonii

- Apocynaceae

- appetite suppressant

- glycosides

obesity

- P57

\section{Abstract \\ $\nabla$}

Hoodia gordonii is a spiny succulent plant popularly consumed for its purported anti-obesity effect. Traditionally used by the Khoi-San of South Africa and Namibia as a hunger and thirst suppressant while on long hunting trips, the commercialisation of this plant has been highly controversial due to intellectual property rights and benefit sharing issues, as well as the fact that several prominent pharmaceutical companies involved in its development have withdrawn their interest. Quality control has been the main focus of scientific studies as the supply of $H$. gordonii plant material is limited due to its sparse geographical distribution, slow maturation rate, need for a permit to cultivate or export material as well

\section{Introduction}

$\nabla$

received Sep. 28, 2010

revised Nov. 25, 2010

accepted Nov. 27, 2010

Bibliography

DOI http://dx.doi.org/

10.1055/s-0030-1250643

Published online January 21,

2011

Planta Med 2011; 77 :

1149-1160 @ Georg Thieme Verlag KG Stuttgart · New York ·

ISSN 0032-0943

Correspondence

Alvaro M. Viljoen

Department

of Pharmaceutical Sciences

Faculty of Science,

Tshwane University

of Technology

Private Bag X680

Pretoria 0001

South Africa

Phone: + 27123826360

Fax: + 27123826243

viljoenam@tut.ac.za
Hoodia gordonii (Masson) Sweet ex Decne. is a spiny succulent plant traditionally used by the Khoi-San of South Africa and Namibia to suppress hunger and thirst while on long hunting trips or in times of famine [1]. Not surprisingly, research and commercial interest was sparked by its antiobesity activity. Obesity has become one of the most common health concerns of modern times. In 2005 it was estimated that 1.6 billion adults were overweight globally with at least 400 million classified as obese. The number of obese teenagers and children in particular has increased dramatically in recent years leading to a heightened awareness of what should be considered a global epidemic. At least 20 million children under the age of five years were overweight in 2005. Obesity is associated with and can lead to many disease conditions including type-2 diabetes, cardiovascular disease, hypertension, sleep apnoea, and cerebrovascular accidents amongst many others [2]. The commercial market for anti- as high public demand, contributing to adulteration of a large amount of products. Despite the isolation of numerous steroidal glycosides from $H$. gordonii, the main focus has been on the pregnane glycoside P57, considered to be the active ingredient and marker molecule to determine quality of raw material and products. Publications based on scientific studies of key aspects such as in vivo biopharmaceutics, the biological activity of all chemical constituents, clinical efficacy, and especially safety are insufficient or completely absent causing great concern as $H$. gordonii is one of the most widely consumed anti-obesity products of natural origin. This review offers an up-to-date overview of all the current available knowledge pertaining to $H$. gordonii achieved by systematic analysis of the available literature.

obesity preparations is enormous due to general public awareness of the ill-effects of obesity and the general perception that being obese is less than attractive. This multibillion dollar industry expands almost on a daily basis as new "miracle cure" products become available. $H$. gordonii supplements are extremely popular, have been well advertised and even sensationalised, using prominent celebrity figures as a marketing tool. The development and commercialisation of $H$. gordonii and P57, the purported active ingredient, has been fraught with controversy due to questions about intellectual property rights and difficulty in product development resulting in the withdrawal of several well-known pharmaceutical companies from $H$. gordonii projects [1]. Since the isolation of P57 [3], many other glycosides have been isolated from $H$. gordonii [4-8], but scientific anti-obesity data is only available on P57, and the evidence of pharmacologic activity that has been published is not nearly sufficient to validate its worldwide consumption. Aspects that should be investigated prior to commercialisation 
of products, such as bioavailability of the active ingredient, have been neglected as research has mostly been focused on quality control issues due to the high reported rate of adulteration of commercially available $H$. gordonii products. Adulteration is caused by several factors including unscrupulous companies concerned only with profit, the limited availability of $H$. gordonii, the slow maturation cycle of the plant, the need for a CITES (Convention on International Trade in Endangered Species) permit to cultivate and export raw material and high demand by consumers [9]. This review offers an up-to-date overview of the plant $H$. gordonii, important issues regarding its use in commercial products, and all scientific studies performed to investigate different aspects of this plant and its phytoconstituents.

\section{Botanical Aspects}

$\nabla$

\section{Description and classification}

H. gordonii (Masson) Sweet ex Decne. is a spiny succulent plant with rows of small thorns present along the fleshy, grey-green to grey-brown stems ( $\bullet$ Fig. 1). Only one stem is produced in the early stages but as the plant matures as many as 50 individual branches are formed from the common base. It is usually about as wide as it is tall and can attain a height of up to one metre. The large flowers, borne on or near the terminal apex, are usually flesh-coloured but more intense purple-red flowers are found in some Namibian populations. Variation in flower size is also common (50-100 mm) with flowers decreasing in size as the flowering period advances. The plant usually flowers in August or September, and the large number of flowers almost completely obscures the stems. An unpleasant smell resembling decaying flesh attracts flies and blowflies to the flowers for pollination. The seed capsules, produced in October and November, resemble antelope or goat horns and contain numerous flat, light brown seeds with silky seed hairs attached to one end [10-12].

Hoodia gordonii is part of the genus Hoodia classified as stapeliads within the tribe Ceropegieae of the subfamily Asclepiadoideae belonging to the Apocynaceae family. The previous classification of Trichocaulon is not recognised as all Trichocaulon species were reclassified to Hoodia and Hoodia is no longer considered part of the Asclepiadaceae. The complete botanical name Hoodia gordonii (Masson) Sweet ex Decne. was based on the discoveries of several people. Hoodia pilifera was the first Hoodia species to be discovered by Carl P. Thunberg and Francis Masson in 1774. Robert Gordon observed a Hoodia species in 1779 and made a drawing of the plant which was published by Masson described as Stapelia gordonii Masson. Robert Sweet of England placed Stapelia gordonii into a new genus in 1830. The genus was Hoodia, named after Mr. Hood, a well-known succulent grower in Britain. Finally, Hoodia gordonii was first validly published by Joseph Decaisne in 1844 after the previous generic names were declared invalid $[11,13]$.

\section{Geographical distribution and habitat}

$H$. gordonii is widely distributed throughout South Africa and Namibia ( Fig. 2). It grows in parts of the western Cape, the north and northwestern regions of the northern Cape as far as Kimberley, and just into the southmost parts of the Free State as well as in south-western Namibia. It has a wide tolerance of growing habitats and can survive extreme heat $\left(>40^{\circ} \mathrm{C}\right)$ as well as relatively low temperatures $\left(-3^{\circ} \mathrm{C}\right)$ but is susceptible to frost and mainly grows in summer rainfall areas. It is found in a variety of

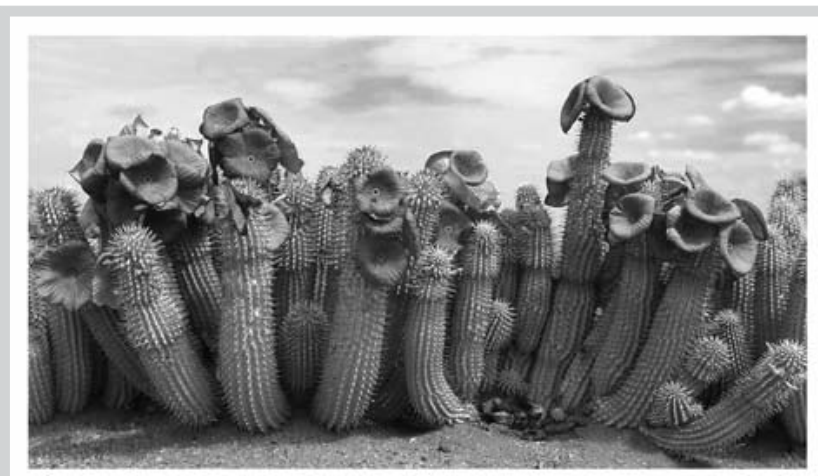

Fig. 1 H. gordonii plant in flower (photograph by Alvaro Viljoen).

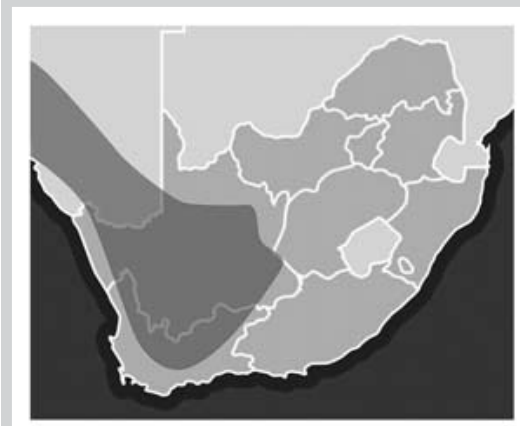

Fig. 2 The natural distribution of $H$. gordonii indicated in grey shading.

habitats such as dry sand, stony slopes or barren, flat areas. Cultivation starts from seeds and is challenging as the plant is slow to mature and needs a lot of care, attention, and protection $[11,12$, 14].

\section{Ethnopharmacology}

Hoodia species are reported to have been consumed by the KhoiSan people of South Africa and Namibia as appetite and thirst suppressants during long hunting trips and when food supplies were low [1]. Usually, a small piece of the stem is consumed fresh after peeling to remove the thorns. Hoodia currori, $H$. flava, $H$. gordonii, and $H$. pilifera have all been consumed fresh as appetite and thirst suppressants, and $H$. currori has been used to treat indigestion, hypertension, diabetes, and stomachache while Hoodia officinalis subsp. officinalis was used to treat pulmonary tuberculosis. According to records, H. piliferum ("ghaap") was consumed more often as it has a cool and watery taste, while $H$. gordonii has a persistent bitter taste and was considered inferior, emphasised by the disparaging vernacular names such as "muishondghaap" and "jakkalsghaap" referring to it only being fit for consumption by animals. However, it is said that the bitterness is less prominent after good rains and the juicy stems would then be eaten raw or cooked. Adding to confusion, several species of stapeliads are referred to vernacularly as "ghaap" $[1,10,13,15,16]$. In many papers on $H$. gordonii it is wrongly stated that it was also used as a cure for abdominal cramps, diabetes, indigestion, hypertension, and so forth, but these applications are in fact attributed to other Hoodia species as mentioned. The source quoted refers to Hoodia species in general, and these uses as well as the uses for H. gordonii are described in a paper by Van Heerden [13]. From this detailed ethnopharmacological account, $H$. gordonii was also used 
for the treatment of tuberculosis, and the honey from the flowers could be used to treat cancer $[13,17]$.

\section{Commercialisation}

- Fig. 3 depicts the timeline of the most important developments in the research and commercial development of $H$. gordonii. The use of Hoodia species, especially $H$. pilifera, by the Khoi-San as a source of food and as a water substitute was recorded in 1932 and 1937. Due to these records, the Council for Scientific and Industrial Research (CSIR) in South Africa included Hoodia species in an investigation of edible wild plants in 1963. The CSIR further investigated the appetite-suppressant activity of extracts of Hoodia species and made a breakthrough with the structure elucidation of compound 1 (P57AS3 commonly known as P57) which was patented in South Africa in 1995. In 1998, this was followed by a patent granted by the World Intellectual Property Organisation on pharmaceutical compositions with appetite suppressant activity. In the same year a licensing agreement to further develop P57 was signed between the CSIR and Phytopharm. Phytopharm, a British pharmaceutical company specialising in phytomedicines, in turn sublicensed the pharmaceutical company Pfizer for further development and commercialisation. Due to a merger between Pfizer and Pharmacia in 2003, the nutraceuticals branch responsible for the development of P57 was closed and Pfizer therefore was not interested in $\mathrm{H}$. gordonii-related research $[1,13,18]$. There were also unconfirmed reports that additional reasons for this discontinuation in research on $H$. gordonii included difficulty in synthesising the P57 molecule and that the synthetic molecules were not as effective as the natural molecules [1,14]. In 2004, the patent was licensed to Unilever for incorporation of $H$. gordonii extracts into food products to produce functional foods. Despite having invested vast sums of money in this project including the development of an extraction facility, these plans were abandoned in December 2008 due to safety and efficacy concerns. Unilever also terminated all activities related to Hoodia in South Africa as of 31 March 2009. Phytopharm remains optimistic about the Hoodia programme and insists that it will find other partners for further development of what should be a very lucrative industry [18]. Among the most disappointed by the slow progress of Phytopharm to develop a commercial product from $H$. gordonii are the San people who claim to own the intellectual property to the discovery of the appetite-suppressant properties of Hoodia.

\section{Intellectual property rights and benefit sharing issues}

The San, more popularly known as "Bushmen", are the oldest inhabitants of Africa and possess a wealth of knowledge about local biodiversity in Botswana, Namibia, South Africa, and Angola. These hunter-gatherers used to live in small nomadic groups covering a vast expanse of land, but oppression, genocide, and dispossession has led to loss of land, culture, and identity. Only a minority of the San people have secured rights to live on their own land, while others work as labourers on commercial game/cattle ranches or reside in government resettlement villages. The common factor among all San is the hopeless poverty they live in. The use of Hoodia by the San as a thirst and appetite suppressant is undisputed. Records of this knowledge resulted in subsequent research and patents on Hoodia and licensing agreements for its commercialisation were granted without the knowledge of the San who are considered the originators of this knowledge. Until 2001, development and commercialisation continued without acknowledgement of the San leading them to launch a painstakingly long and hard challenge against the CSIR on their Hoodia patent. This only occurred after the foreign media were informed of this potential exploitation of the San people, depicted as poor and emaciated, in stark contrast with images of rich obese Westerners. This act portrayed as biopiracy by large pharmaceutical companies resulted in an eagerly followed high-profile law suit and forced negotiations concerning benefit-sharing [18]. This case raised issues on ownership of knowledge and resources. Previously, renewable resources such as plants, animals, and microorganisms were regarded as common heritage of humankind. Any person could remove these resources from nature and use them to develop commercial products. However, the establishment of the Convention on Biological Diversity (CBD) in 1992 declared that biological resources fall under the sovereignty of the states. The convention encompasses the conservation of biological diversity and the sustainable use of its components, as well as fair and equitable sharing of benefits. Traditional knowledge is considered to be removed from the common heritage of humankind and therefore is subject to formal prior informed consent, and benefits must be shared equitably. The San opted to share in the royalties rather than continue with an expensive law suit to

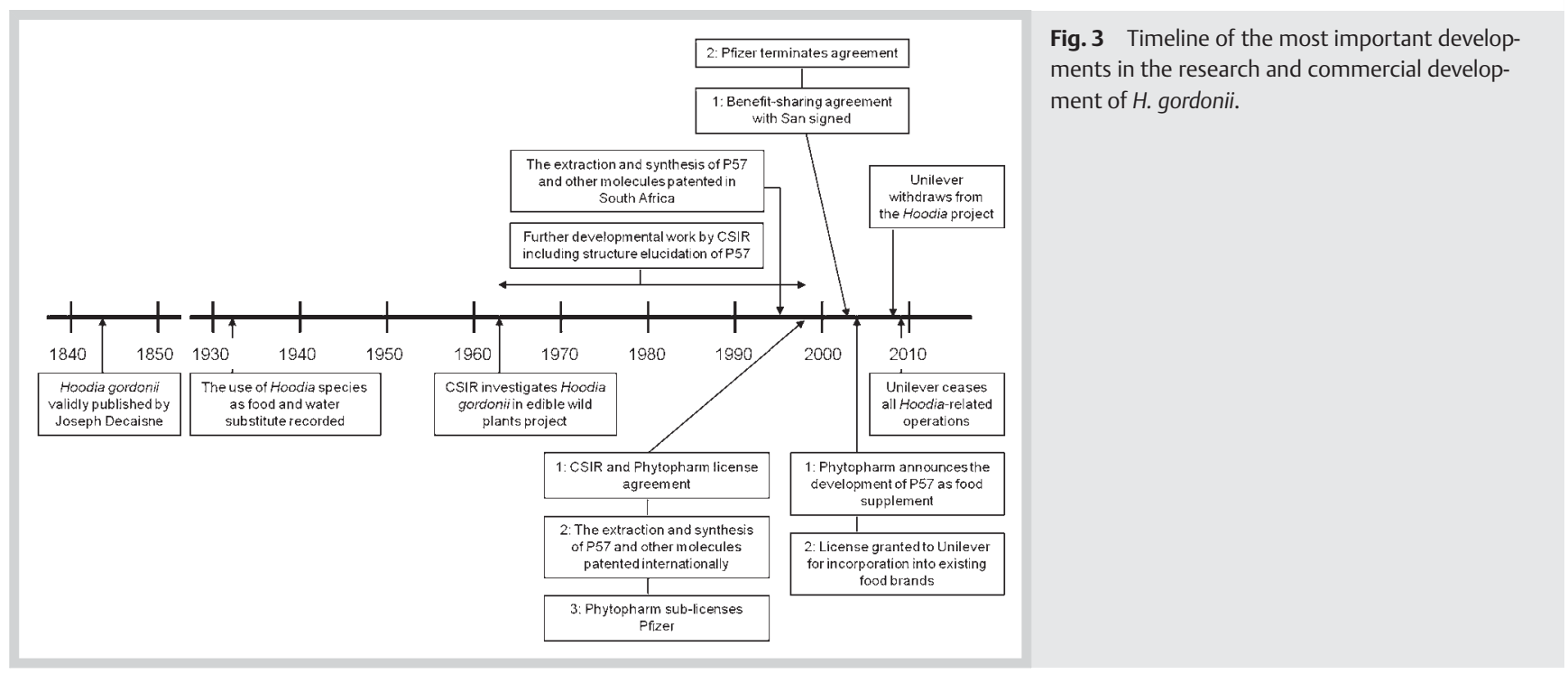


prevent use of their knowledge culminating in a mutual benefit agreement which was finally signed in 2003. It was important to ensure that the agreement was inclusive of all of the San people and would benefit all equally as the traditional knowledge is extended into several countries [18]. According to the agreement between the CSIR, its licensees, and the South African San Council, the parties will share royalties from potential sales of drugs or other products derived from Hoodia. The money, $8 \%$ of all payments that the CSIR receives from licensees and 6\% of all royalties after commercialisation, will be paid into a Trust controlled by the San to be used to the benefit of the San people [1]. However, the payment of these royalties is currently not applicable since no products have yet been developed out of this agreement. It is clear that the commodification of traditional knowledge is complex, and the laws concerning intellectual property rights are continuously evolving to adapt to issues relevant to each natural resource.

\section{Phytochemistry}

The Van Heerden group pioneered the phytochemistry by isolating two steroidal glycosides named compounds 1 and 2 from $H$. gordonii and $H$. pilifera extracts [16]. Compound $\mathbf{1}$ is referred to as P57AS3, more commonly known as P57 ( Fig. 4) [16]. Since then, many new structural analogues have been isolated from Hoodia gordonii: eleven oxypregnane glycosides - hoodigoside A-K [4]; ten pregnane glycosides - hoodigoside L-U [5]; ten steroidal glycosides - gordonoside A-I, L [6]; seven pregnane glycosides - hoodigoside V-Z and hoodistanaloside A-B [8]; and formulae 7-8 and 12 [7]. The backbone chemical structures of these compounds are the aglycones hoodigogenin A, calogenin, hoodistanal, dehydrohoodistanal, and isoramanone formed as a result of acid and/or enzymatic hydrolysis. The respective analogues and their aglycones are indicated in $\odot$ Fig. 4. The discovery of numerous new compounds provides the opportunity for research into their biological activity and has also been used to develop new quality control methods for $H$. gordonii products [19].

\section{Biological Activity \\ V}

Anti-obesity activity

The in vivo anti-obesity effect of $H$. gordonii and/or P57 has been studied in rats and chickens. The first scientific reports of antiobesity activity were by Tulp et al. $[20,21]$ but only in the form of abstracts severely limiting the value in terms of interpretation of the results due to the lack of detail. In addition, the administration of Hoodia species is indicated, not specifically $H$. gordonii itself. In the first abstract it is mentioned that food intake in both lean and obese rats was voluntarily reduced with a concomitant reduction in body weight. Marked reduction in obese and moderate reduction in lean rats was noted. The effective dose was determined to be $1.8-2.7 \mathrm{~g} / \mathrm{kg}$ of body weight in rats for various Hoodia species [20]. In the follow-up study, $2 \%(\mathrm{w} / \mathrm{v})$ aqueous homogenate of dehydrated Hoodia was administered to lean and obese mice resulting in a decreased food intake within 48 hours. The body weight of the obese rats, initially twice the weight of the lean rats, decreased to near normal weights after 2-3 weeks of Hoodia feeding, and the body fat mass in lean and obese rats were decreased compared to rats fed a normal diet [21]. Experiments performed and included in a US patent application [3] revealed a reduction in food intake, increased water consumption, reduced mean body mass gain, and body mass loss in some of the groups.
These results were reported in a scientific paper in 2007 [16]. P57 was orally administered to female rats in 5 different dosages $(6.25-50 \mathrm{mg} / \mathrm{kg})$ for 3 consecutive days, and the effects were monitored for 8 days. The effect was compared to that of fenfluramine, a pharmaceutical anti-obesity drug. While both fenfluramine and P57 administration resulted in decreased food intake, a higher body mass gain was noted for fenfluramine compared to that for P57, though less than for the control group [16]. The only in vitro study related to anti-obesity activity was part of an attempt to determine the mechanism of action of P57 undertaken in 2004. Following incubation of P57 with hypothalamic neurons in culture, a $50-150 \%$ increase in adenosine triphosphate (ATP) content was recorded. In the in vivo (rat) part of the study, P57 was injected into the third ventricle of the brain (i.c. v.). Food intake monitored over a 24 -hour period was reduced by $40-60 \%$ with a dose-dependent $(0.4-40 \mathrm{nmol})$ effect. Two P57 derivatives, P57ASA and P57NS5, tested at $40 \mathrm{nmol}$ in DMSO showed no effect. Hypothalamic ATP content was increased after i.c. v. injection in rats maintained on a normal diet, and the expected decrease in ATP in hypocaloric rats was blocked by injection of P57. From these results the authors concluded that P57 has a likely mechanism of action in the central nervous system as suggested by the effects on the hypothalamic neurons and hypothalamus as the hypothalamus is an area of the brain involved in the control of hunger, appetite, and temperature control. However, this does not preclude any peripheral mechanisms of action [22]. In Ross 308 broiler chickens, daily supplementation with a $H$. gordonii meal (300 mg) had no effect on feed intake, digestibility, and growth but reduced fat pad weights by $40 \%$. The carcass quality and feed efficiency is reduced by excessive fat, therefore $\mathrm{H}$. gordonii supplementation may have a beneficial effect though the mechanism needs to be further investigated [23].

No data on clinical studies in humans have been reported in scientific papers, partly due to the proprietary nature of the research. Phytopharm reported that double-blind, placebo-controlled studies were performed on 20 obese free-feeding volunteers. They were treated with an extract of $H$. gordonii; participants were not advised to follow a specific eating plan, and exercise was not required. The participants receiving the extract voluntarily reduced their caloric intake by approximately 1000 calories per day, despite the fact that food was readily available. The decreased food intake resulted in weight loss of about $2 \mathrm{~kg}$ and a beneficial reduction in blood glucose and triglycerides $[1,14]$. The Phytopharm press release relating to this study has been removed from their website. In another paper on $H$. gordonii, the authors report on an open-label observational study performed by one of the authors. A specific product called Hoodia Supreme ${ }^{\circledR}$ said to contain $400 \mathrm{mg}$ of pure $H$. gordonii raw material per capsule was supplied to eight obese participants twice daily for a 4week period. Data was gathered by direct questioning on eating habits as well as weight measurement. Weight loss (2-15 pounds), reduction in appetite, a voluntary reduction in calorie intake (estimated 500-1000 calories/day), a reduction in craving for carbohydrate-containing foods, and a mild energising effect were reported. In the same paper there is reference to a study by Goldfarb, but the original source as mentioned in the references could not be located on the internet. It stated that 7 participants receiving DEX-L10 ${ }^{\circledR}$ containing $500 \mathrm{mg}$ of $H$. gordonii for a 28-day period reported a median weight loss of 10 pounds with no alteration in dietary or daily activity habits [24]. The information related to clinical studies is scarce, and for most of these studies the data are not currently accessible, which raises even 


$$
\begin{aligned}
& \underbrace{}_{\mathrm{OH}} \\
& \text { P57/Compound 1/Formula } 6^{\circ} \\
& \text { Hoodigoside } \mathrm{B}^{*} \\
& \text { 等 } \\
& \text { Hoodignside } D^{\circ} \\
& \text { Ho } \sum_{\mathrm{OH}} \\
& \mathrm{CH}_{\mathrm{OH}} \mathrm{OCH}_{3} \\
& \text { Hoodigoside C/Gordonoside C' } \\
& \text { 等 } \\
& \text { Hoodigoside E/Gordonoside } \mathrm{H}^{\circ} \\
& \text { 管 } \\
& \text { Hoodigoside F- }
\end{aligned}
$$

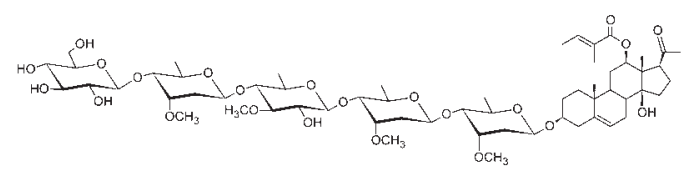

$$
\begin{aligned}
& \text { Hoodigoside } \mathrm{G}^{\circ} \\
& \text { 等 } \\
& \text { Hoodigoside J } \\
& \underbrace{\mathrm{OHO}}_{\mathrm{OH}} \\
& \text { Hoodigoside } \mathrm{K}^{*} \\
& { }_{\mathrm{OH}_{3} \mathrm{CO}} \mathrm{COL}_{\mathrm{O}} \\
& \text { Hoodigoside N" }
\end{aligned}
$$

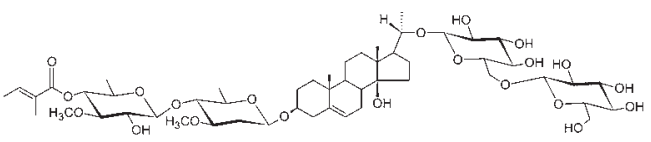

$$
\begin{aligned}
& \text { Hoodigoside } \mathrm{O}^{*} \\
& { }_{\text {Hoodigoside } \mathrm{P}^{*}}
\end{aligned}
$$

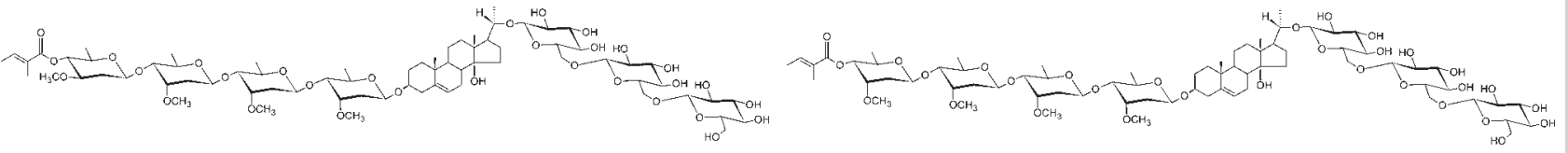

$$
\begin{aligned}
& \text { Hoodigoside } \mathrm{S}^{*}
\end{aligned}
$$

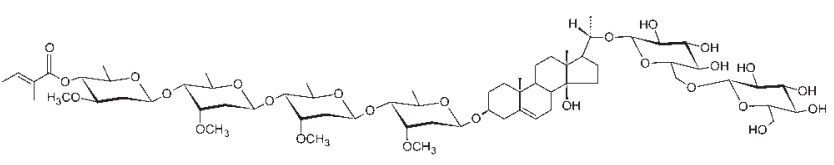

$$
\begin{aligned}
& \text { Hoodigoside } \mathrm{T}^{*} \\
& \text { Hoodigoside } U^{4}
\end{aligned}
$$
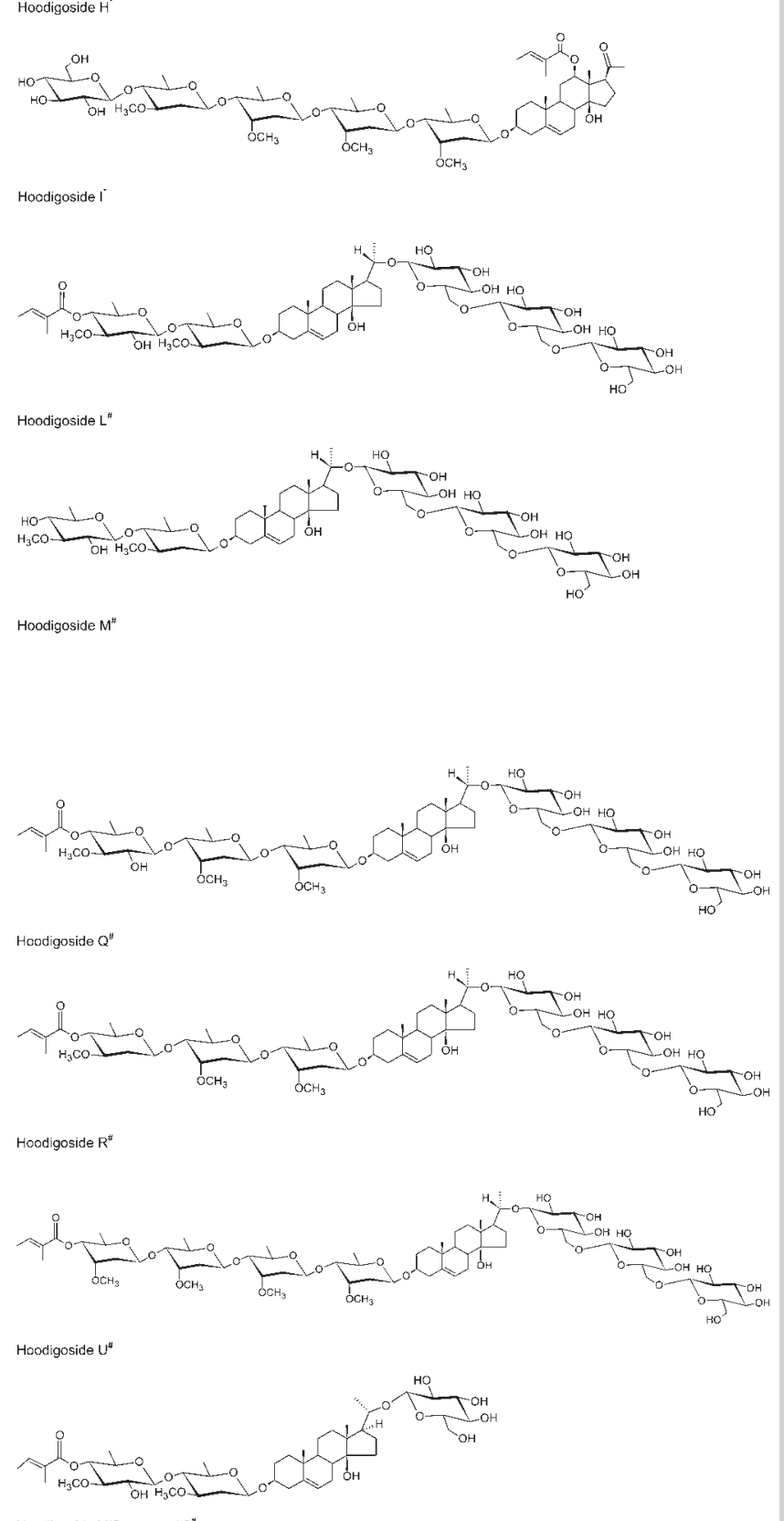

Fig. 4 Chemical structures of the steroidal glycosides isolated from $\mathrm{H}$. gordonii with their corresponding aglycones indicated $\left({ }^{*}, \#, \$, @, \wedge\right)$. Continued on next page. 


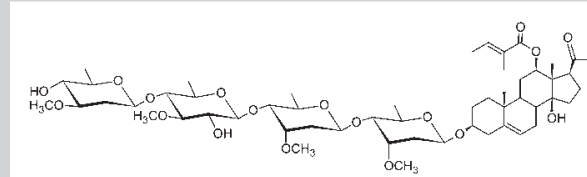

Hoodigoside W

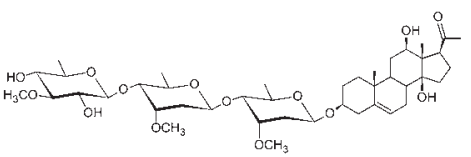

Hoodigoside $X^{s}$

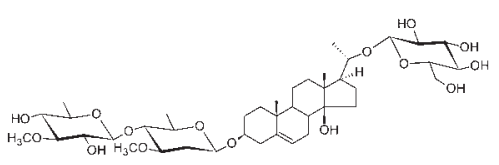

Hoodigoside $Y^{*}$

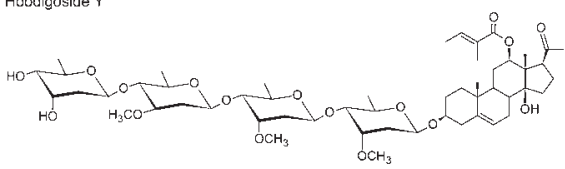

Gordonoside $D^{\circ}$

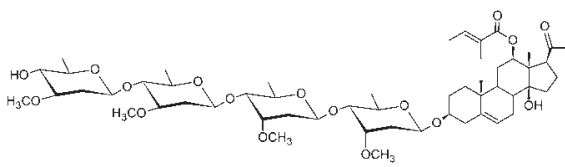

Gordonoside $E^{\cdot}$

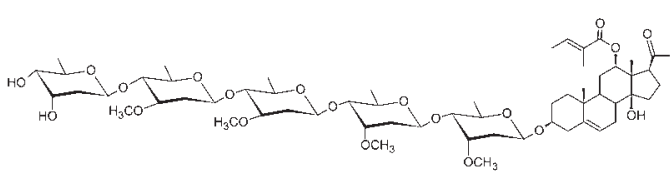

Gordonoside |

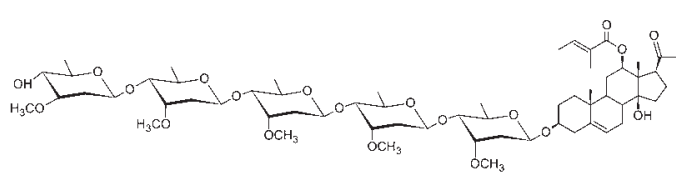

Gordonoside LFFormula 11'

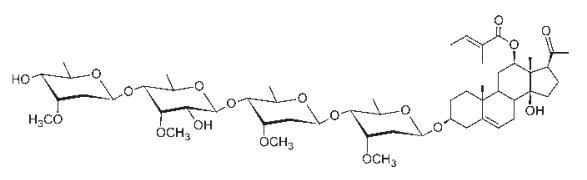

Formula ?

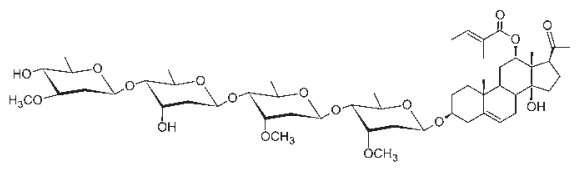

Formula $8^{\circ}$

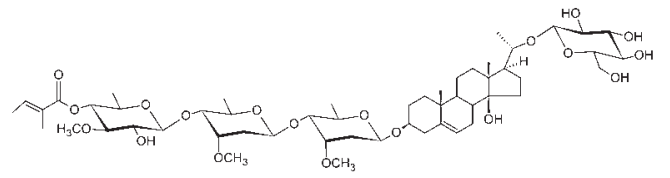

Hoodigoside Z"

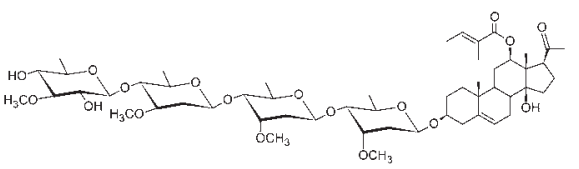

Gordonoside B

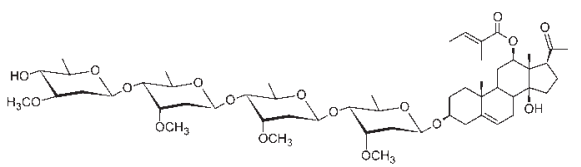

Gordonoside FiFormula $9^{\circ}$

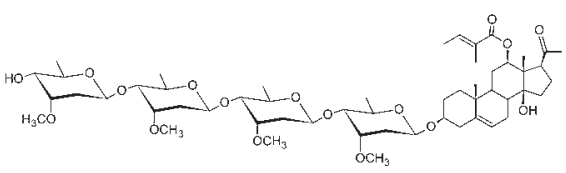

Gordonoside Giformula $10^{\circ}$

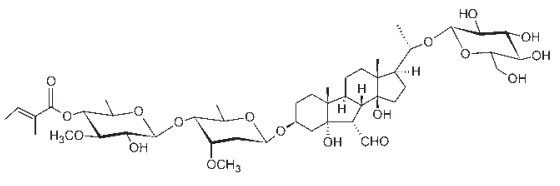

Hoodistanaloside $\mathrm{A}^{\varrho}$

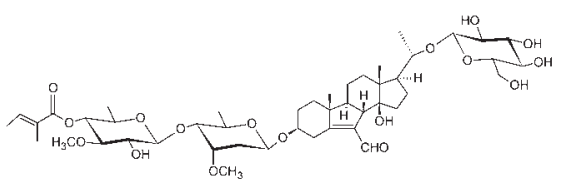

Hoodistanaloside $\mathrm{B}^{\wedge}$

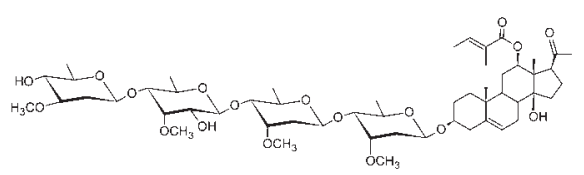

Formula 12

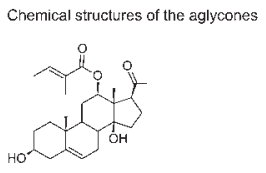

Hoodigogenin $\mathrm{A}^{*} /$ Gordonosice $\mathrm{A}$
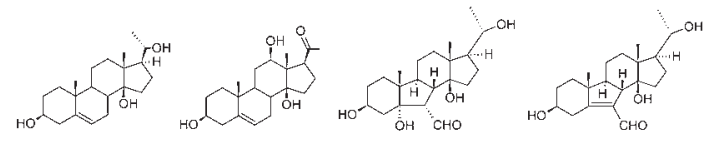

Calogenin"

Isoramanon $e^{\text {s }}$

Fig. 4 (continued) Chemical structures of the steroidal glycosides isolated from H. gordonii with their corresponding aglycones indicated (*, \#, s, @, ^).

more questions about the use of $H$. gordonii as an anti-obesity preparation. It is evident that proper clinical studies in humans are needed to validate claimed anti-obesity effects. A summary of the studies on the anti-obesity activity of $H$. gordonii and P57 is shown in $\bullet$ Table 1.
Other biological activities

Hoodigosides A-K and P57 were evaluated for cytotoxic and antioxidant properties in vitro. The compounds were not cytotoxic and did not show any inhibition of growth against a panel of cell lines including SK-MEL, KB, BT-549, SKOV-3, VERO, and LLC-PK1 up to the highest concentration of $25 \mu \mathrm{g} / \mathrm{mL}$. No antioxidant ac- 
Table 1 Studies on the in vivo anti-obesity activity of $H$. gordonii and P57.

\begin{tabular}{|c|c|c|c|c|}
\hline In vitro/In vivo & Tested in: & $\begin{array}{l}\text { Hoodia gordonii/ } \\
\text { P57 and administration }\end{array}$ & Effect(s) & References \\
\hline \multirow[t]{4}{*}{ In vivo (animals) } & Rats & $\begin{array}{l}\text { Hoodia species crude aqueous } \\
\text { homogenate/semi-purified } \\
\text { extracts (oral) }\end{array}$ & $\begin{array}{l}\text { Reduced food intake, body weight and } \\
\text { gonadal fat pad weights, blood glucose }\end{array}$ & {$[20,21]$} \\
\hline & Rats & P57 (oral gavage) & Reduction in food intake, body weight & {$[3,16]$} \\
\hline & Rats & P57 (i.c.v injection) & Reduction in food intake & {$[22]$} \\
\hline & Chickens & H. gordonii meal (oral) & Reduction of fat pad weights & [23] \\
\hline \multirow[t]{3}{*}{ In vivo (humans) } & Obese males (20) & Hoodia extract (oral) & $\begin{array}{l}\text { Reduction in food intake, body weight, } \\
\text { blood glucose and triglycerides* }\end{array}$ & {$[1,14]$} \\
\hline & $\begin{array}{l}\text { Obese subjects ( } 2 \text { male, } \\
6 \text { female) }\end{array}$ & $\begin{array}{l}\text { Hoodia Supreme }{ }^{\circledR} \text { capsules } \\
\text { containing Hoodia gordonii } \\
\text { raw material (oral) }\end{array}$ & $\begin{array}{l}\text { Reduction in food intake, appetite, body } \\
\text { weight, craving for carbohydrates and a } \\
\text { mild energising effect reported }\end{array}$ & [24] \\
\hline & Overweight subjects (7) & $\begin{array}{l}\text { DEX-L10 } 0^{\circledR} \text { capsules containing Hood- } \\
\text { ia gordonii raw material (oral) }\end{array}$ & $\begin{array}{l}\text { Reduction in body weight and } \\
\text { calorie intake* }\end{array}$ & [24] \\
\hline
\end{tabular}

* Could not be verified as the original source, as cited, could not be located

tivity was recorded in HL-60 cells, and intracellular reactive oxygen species (ROS) generation was not inhibited [4]. In a US patent application by Hakkinen et al. [25], the gastroprotective effect of P57 and the effects on gastric acid secretion and gastric motility were described. Gastric damage due to oral administration of aspirin was reduced by $91.5 \%$ for P57 and $93.2 \%$ for cimetidine. Oral administration of a spray dried extract at a dose of $50 \mathrm{mg} / \mathrm{kg}$ inhibited acid output by $50 \%$ and gastric emptying by $26 \%$. Intraduodenal administration of purified P57 at a dose of $10 \mathrm{mg} / \mathrm{kg}$ decreased acid output by $88 \%$ while subcutaneous administration decreased acid output by $43 \%$ [25]. These effects are promising but Madgula et al. [26] found 100\% degradation of P57 in simulated gastric fluid, which raise more questions about the actual active molecule. Antidiabetic activity has also been claimed, but ethnopharmacologically it is $H$. currori that has been used as an antidiabetic [13]. In 2006, a patent was filed for antidiabetic properties from extracts of Hoodia. An acute $(20-160 \mathrm{mg} / \mathrm{kg}$ ) and chronic study (60 and $120 \mathrm{mg} / \mathrm{kg}$ ) was conducted with P57 (compound 1), and food and water intake, body weight, glucose, insulin, and leptin levels in male diabetic ZDF rats were assessed. In the chronic study the doses were reduced to 60 and $30 \mathrm{mg} / \mathrm{kg}$ on day 7 due to concerns about the $50 \%$ reduction in food intake. The results showed that P57 had positive effects on body weight, normal glycaemia was maintained, and water intake of diabetic rats was reduced within 4 days to that of the control lean rats [27].

\section{Biopharmaceutical Aspects \\ $\nabla$}

\section{Pharmacokinetics of hoodigogenin A}

Hoodigogenin A, the aglycone of P57, is formed as a result of acid and/or enzymatic hydrolysis of P57. Hydrolysis of P57 will certainly take place in the gastrointestinal tract fluids after oral administration, indicating the importance of studying the pharmacokinetics of this compound. It has been documented that aglycones are more easily absorbed than their glycosidic counterparts. The hydrophobic nature of aglycones enables passive diffusion through biological membranes, while the water solubility is higher for the glycosides and the sugar linkages restrict passive diffusion. To assess the gastric and intestinal stability of P57 and hoodigogenin A, they were incubated with simulated gastric fluid (SGF) and simulated intestinal fluid (SIF). Incubation of P57 with
SGF for 60 minutes exhibited the loss of this compound with the simultaneous appearance of hoodigogenin A. When hoodigoge$\operatorname{nin}$ A itself was incubated with SGF, its concentration remained relatively constant indicating stability in SGF. Incubation with SIF for 180 minutes caused degradation of P57, but concomitant formation of hoodigogenin A was not noted. Hoodigogenin A itself was stable in SIF. The degradation of P57 was $100 \%$ in SGF and $8.6 \%$ in SIF while for hoodigogenin A the degradation was $2 \%$ in SGF and $1 \%$ in SIF [26]. Bidirectional transport studies with hoodigogenin A across Caco-2 cell monolayers categorised it as a highly permeable molecule after comparison to propranolol (high solubility, high permeability) and atenolol (high solubility, low permeability). The substantial transport was linear for the test period of two hours. To assess blood brain barrier (BBB) permeability, the MDR1-MDCK cell model was used. Caffeine, used as the CNS positive drug, showed high permeability and bidirectional transport while the CNS negative drug atenolol showed low permeability and bidirectional transport. It has been previously reported that compounds exhibiting $\mathrm{P}_{\mathrm{app}}$ values of less than $1 \times 10^{-6} \mathrm{~cm} / \mathrm{sec}$ such as atenolol are unable to penetrate the $\mathrm{BBB}$. According to the transport results, hoodigogenin A should be able to penetrate the $\mathrm{BBB}$ due to its $\mathrm{P}_{\mathrm{app}}$ value of $5.18 \pm$ $0.23 \times 10^{-6} \mathrm{~cm} / \mathrm{sec}$, especially in conjunction with its lipophilicity. The oral bioavailability of hoodigogenin A may be severely limited by extensive metabolism in the human liver as indicated by biotransformation in microsomes and S9 fractions and the fact that it is highly protein bound (92\%) leading to low availability of free molecules that are responsible for the pharmacological activity. In addition, hoodigogenin $\mathrm{A}$ is a moderate inhibitor $\left(\mathrm{IC}_{50}=3 \mu \mathrm{M}\right)$ of CYP3A4, indicating a risk of interaction with other drugs, though the inhibition was considerably lower than that of the known inhibitor ketoconazole $\left(\mathrm{IC}_{50}=0.05 \mu \mathrm{M}\right)$ [26].

\section{Pharmacokinetics of P57}

The investigation of the intestinal transport of P57 in three concentrations $(50,100,200 \mu \mathrm{M})$ across Caco-2 cell monolayers revealed low transport in the apical to basolateral (absorptive) direction of $1.7-1.9 \%$ with no measurable transport at $50 \mu \mathrm{M}$. However, transport in the basolateral to apical (secretory) direction was $6.7-18.7 \%$, indicating a significant efflux of P57 by active membrane transporters. In the presence of inhibitors of two membrane transporters namely P-glycoprotein (verapamil) and multidrug resistance-associated protein (MK-571), permeability 
of P57 increased in the absorptive direction indicating it is a substrate of these two membrane transporters. In the absence of these efflux pump inhibitors, P57 permeability was concentration-dependent indicating saturation of transporters. This finding indicates that P57 may have a limited oral bioavailability due to efflux, especially when administered in low concentrations [28] and that P57 itself may be an inhibitor of membrane transporters. P57 was relatively stable in human liver microsomes indicated by the presence of $84 \%$ unchanged P57 at 30 minutes and $58 \%$ at 2 hours. In addition, weak inhibitory activity $\left(\mathrm{IC}_{50}=\right.$ $45 \mu \mathrm{M}$ ) of the CYP3A4 liver enzyme, which is responsible for the metabolism of $50 \%$ of pharmaceuticals, was seen, indicating some potential for herb-drug interactions that may affect the pharmacokinetic profile of drugs administered concomitantly [28]. This in vitro study was followed by an in vivo investigation in CD1 female mice of an oral administration of a methanolic extract of $H$. gordonii (equivalent to a dose $25 \mathrm{mg} / \mathrm{kg}$ P57) and intravenous (IV) administration of purified P57 (25 mg/kg P57). Oral administration revealed a peak plasma concentration after 0.6 hours, complete elimination from the tissues and the plasma after 4 hours and 24 hours, respectively, and moderate bioavailability of $47.5 \%$ [29]. The moderate oral bioavailability is likely to be due to degradation in gastric and intestinal fluids as discussed in the previous section. Low P57 concentrations were noted in kidney and liver tissues with higher concentrations in intestinal tissues. No P57 was detected in the brain tissue, refuting the central mechanism of action previously proposed by MacLean and Luo [22]. However, this mechanism of action was proposed after IV administration. In this previous study, P57 was detected in decreasing concentrations in the kidney, liver, and brain. In addition, the levels of P57 detected in the brain were not as high as reported in the MacLean and Luo study [22]. Elimination from the tissues occurred after 30 minutes from the brain, 2 hours from the liver, and 4 hours from the kidney. After IV administration, P57 was completely eliminated from the plasma within 8 hours, and P57 was extensively distributed extravascularly. The elimination phase half-life was similar for both oral and IV administration, but other parameters varied considerably [29].

\section{Toxicity}

Data pertaining to the toxicity/safety of $H$. gordonii is scarce. In a five-year study in Italy, 233 spontaneous reports on adverse reactions to natural health products were collected and analysed. An anticholinergic effect was noted with one preparation containing $100 \mathrm{mg} \mathrm{H}$. gordonii raw material [30]. However, it also contained $200 \mathrm{mg}$ Ma huang (Ephedra sinica) raw material which most likely caused this effect [31]. Another product containing Hoodia was associated to a case of acute hepatitis, but 6 pharmaceutical preparations were taken concomitantly [30]. Acute toxicity studies were described in a patent application by Van Heerden et al. [3]. A plant extract administered orally to mice in doses of $100 \mathrm{mg} / \mathrm{kg}$ up to $3028.5 \mathrm{mg} / \mathrm{kg}$ revealed no clinical signs of toxicity. Dose-related reversible histopathological liver changes in the form of moderate cloudy swelling and hydropic degeneration of hepatocytes was recorded from a dose of $200 \mathrm{mg} / \mathrm{kg}$. The number of animals used in this study was small ( $n=2$ per dosage group), but the fact that all of the groups except one showed liver changes on histopathological examination warrants further investigation. During anti-obesity activity experiments in congenic lean and obese rats, high quantities of $H$. gordonii were orally administered, and no adverse effects were noted [21]. No adverse effects were reported for the clinical study performed in humans, but it should be kept in mind that not much was reported at all due to the proprietary nature, and the occurrence of side effects is certainly not the type of information a company developing a product would attract attention to. Its traditional use by the Khoi-San also bodes well for safety, but is only applicable to fresh $H$. gordonii and not extracts or molecules isolated from the plant as these would be in a concentrated form.

\section{Quality Control Aspects \\ $\nabla$}

\section{Chromatographic methods}

Liquid chromatography (HPLC/UPLC): The most commonly used method to analyse raw plant material for P57 content is liquid chromatography. As P57 is the only recognised anti-obesity compound in $H$. gordonii, the first methods were focused on its quantification only. When liquid chromatography coupled to ultraviolet detection (LC-UV) is used, detection is done at a wavelength of $220 \mathrm{~nm}$. This absorbance is due to the presence of a tigloyl group, present in all $H$. gordonii steroidal glycosides [32]. Avula et al. [9] developed a method for the quantification of P57 using liquid chromatography electrospray ionisation mass spectrometry (LC-ESI-MS) and liquid chromatography with ultraviolet detection (LC-UV). The LC-MS method had a total run time of 45 minutes including a 5-minute wash and 15-minute calibration period while the total run time for the LC-UV method was 55 minutes. Product testing revealed that 4 of the 6 products tested did not contain P57 or were below the detection limit, and no P57 was detected in the common adulterant Opuntia ficus-indica (prickly pear). The P57 results for LC-UV and LC-MS were very similar, but the limit of detection of LC-MS $(10 \mathrm{ng} / \mathrm{mL})$ was lower than that of LC-UV (100 ng/mL). The same research group discovered many novel compounds from $H$. gordonii and subsequently followed up these discoveries with a chemical fingerprinting technique for Hoodia species and 11 oxypregnane glycosides with LC-UV. The phytochemisty of $H$. gordonii is complex; it contains an abundance of constituents as illustrated by the typical LC-MS chromatogram of $H$. gordonii raw material ( Fig. 5). The LC-MS chromatogram and mass spectrum of P57 is shown in 8 Fig. 6. Due to the complexity of these plant extracts and abundance of similar compounds, the run time was increased to 80 minutes, and various other adjustments to the chromatographic conditions were made. The method could distinguish Hoodia species from 23 other closely related genera, but could not authenticate $H$. gordonii as all 11 compounds were present in all Hoodia species analysed [33]. In a follow-up study, ultra-performance liquid chromatography (UPLC) in combination with UV and MS was used for chemical fingerprinting of Hoodia species (12 hoodigosides) and related genera and the quantification of P57 in several different dosage forms of dietary supplements claiming to contain Hoodia. The use of UPLC enabled a considerable reduction in analysis time from $80 \mathrm{~min}$ for HPLC to $15 \mathrm{~min}$. The UPLC-UV method was used for quantification of P57, and all the plant extracts and products were analysed with UPLC-MS. Of the 35 commercially available products tested, 26 did not show the presence of P57. The nine other products had low levels of P57 and with UPLC-UV one product tested negative for $\mathrm{P} 57$ while its presence was confirmed with the more sensitive UPLC-MS method. This paper also provided extraction methods for the many different dosage forms in which products claiming to contain Hoodia are sold [19]. The research group of Khan et al. [4, 5, 8, 19,26, 28,29] has made valuable contributions to $H$. gordonii knowledge in terms of quality 


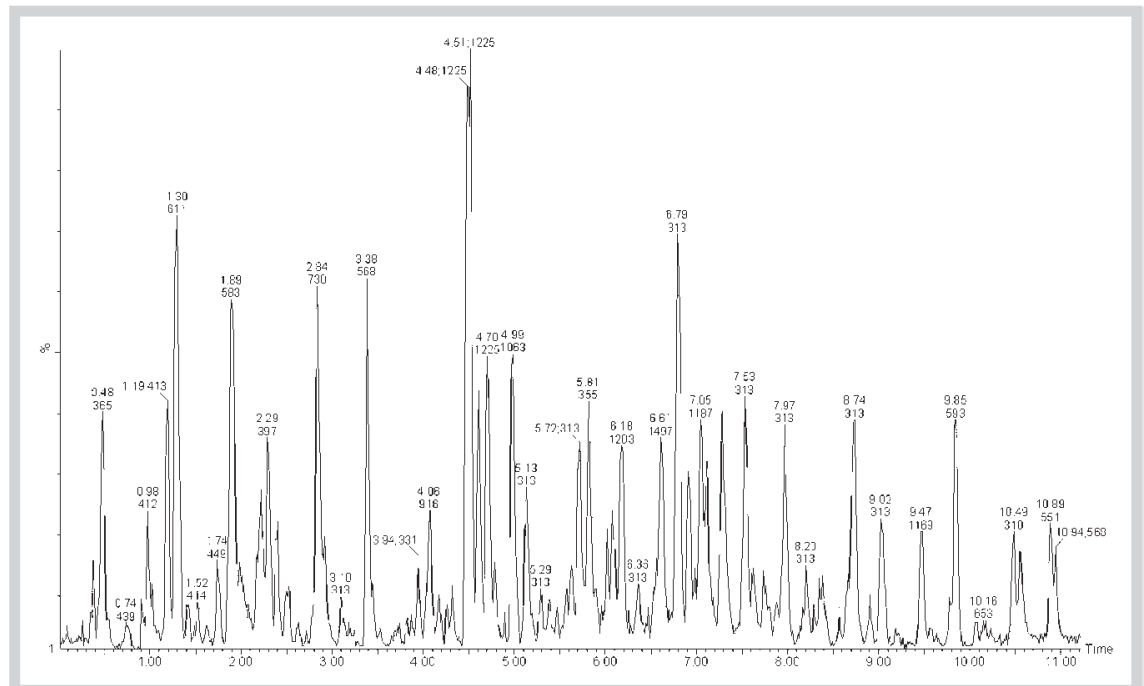

Fig. 5 Typical LC-MS chromatogram of $H$. gordonii raw material indicating retention time and mass $(\mathrm{m} / \mathrm{z})$.

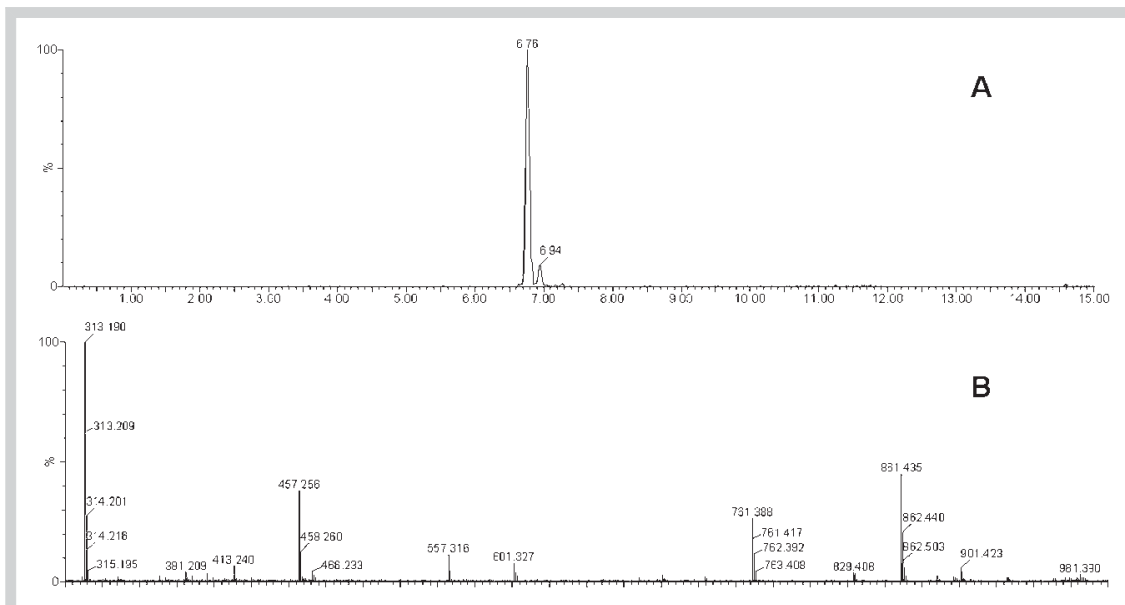

Fig. 6 LC-MS chromatogram (A) and the mass spectrum (B) of P57.

control, isolation of compounds, and biopharmaceutics. Another HPLC-UV quantification method was developed by Janssen et al. [32]. This method can be used to quantify several steroidal glycosides from plant material and even complex food products such as yoghurt and maize oil. However, this paper is more focused on method development, and quantification results as such are not shown. The development of these methods contributes towards the quality control of $H$. gordonii plant material and products. However, liquid chromatography methods are expensive, time-consuming, laborious, and require skilled personnel. Thus, simpler and faster methods of quality control are desirable.

High-performance thin layer chromatography (HPTLC): Several papers discussing the authentication of $H$. gordonii and to detect the presence of P57 have been published. Widmer et al. [34] first investigated the method used by Alkemists Pharmaceuticals, well-known for the authentication of $H$. gordonii raw material, before embarking on the development of their own method. Extraction from raw material and development conditions were optimised and enabled $H$. gordonii to be distinguished from $H$. currorii and $H$. parviflora. They also concluded that $\beta$-sitosterol can be used to check for the presence of P57 as it has the same $\mathrm{R}_{f}$ value [34]. This was criticised in a paper by Rumalla et al. [35] as they mention that using only P57 or a non-specific compound like $\beta$-sitosterol may not establish the complete chromatographic identity of $H$. gordonii which comprises at least two chemically distinct steroidal aglycones. The elegant method developed by Rumalla et al. [35] provided a characteristic fingerprint for Hoodia species, but not $H$. gordonii specifically, with $R_{f}$ values for 11 pregnane glycosides used as standards. The chemical fingerprint of $H$. gordonii was compared with 24 closely related plant species, and none was comparable to $H$. gordonii. Thirteen commercially available products claiming to contain $H$. gordonii were investigated. Of the 13 products tested, 11 products did not contain the pregnane glycosides and P57. This method showed specificity due to the large number of marker compounds overcoming a common HPTLC problem of overlapping bands [35]. Vermaak et al. [36] developed a qualitative analytical method able to confirm the presence of $H$. gordonii and P57 in raw material as well as several product samples. The P57 values in the products varied greatly from 0.000 to $0.304 \%$ as determined by LC-MS. Of the 20 products tested, 6 products had negligible quantities of P57 not detected with the HTPLC method. Three of these products were determined by LC-MS to contain P57 of 0.006, 0.003, and $0.001 \%$ while the other 3 products contained none. Most of the capsule products contained more than $0.100 \%$ P57 while the topical gel, transdermal patch, fruit bar, compote, instant drink mix, and oral strips contained very little or no P57. A typical HPTLC plate from this study of $H$. gordonii raw material, products, and P57 is shown 


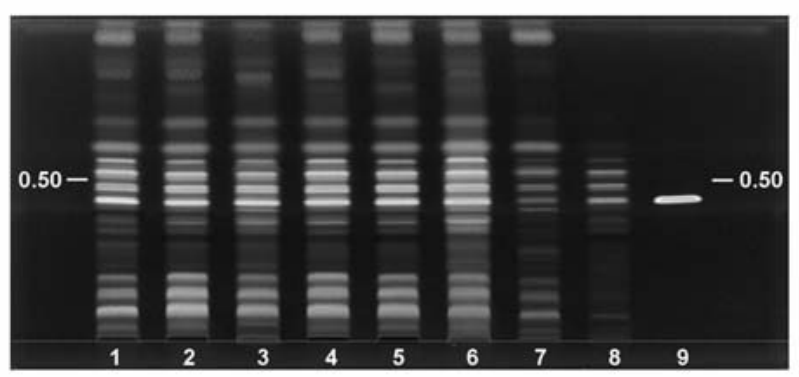

Fig. 7 A typical HPTLC plate viewed under UV $365 \mathrm{~nm}$. Track 1: H. gordonii raw material, track 2-8: H. gordonii products, and track 9: the reference standard P57.

in 1 Fig. 7 [36]. All the HPTLC methods developed provided a faster, cost-effective, and simpler alternative for qualitative analysis compared to liquid chromatography methods. However, distinguishing between the different species remains a challenge as natural variation within plant samples may cause the distinguishing characteristics to be less intense.

Vibrational spectroscopy: Only two papers on the quantification of P57 in $H$. gordonii using vibrational spectroscopy have been published. In the first paper NIR spectroscopy in combination with chemometric data analysis was used to develop a calibration model with Simca-P+11.0.0.0 software for the quantification of P57 in H. gordonii raw material. The dataset consisted of 146 raw material samples for which the P57 content was quantified with LC-MS. After the 2nd derivative preprocessing and using the partial least squares projections to latent structures algorithm, it was concluded that the model could accurately predict the amount of P57 in a raw material sample with a regression coefficient $\left(R^{2}\right)$ of 0.9629 and a root mean square error of prediction (RMSEP) of $0.03 \%$. In addition, it was found that mid-infrared spectroscopy does not seem suitable to quantify P57 [37]. Raman spectroscopy was used to quantify P57 using a dataset of raw powdered plant samples for which P57 was quantified with LC-MS. Chemometric analysis methods were applied to develop a PLS calibration model with orthogonal scatter correction preprocessing. The $\mathrm{R}^{2}$ value in this case was 0.9986 and the RMSEP value $0.004 \%$. The lower RMSEP value especially indicated that this method was superior to the NIR spectroscopy method. In addition, Raman mapping was used to determine the spatial distribution of P57 in a cross-section of fresh $\mathrm{H}$. gordonii stem. The results, corroborated with LC-MS analysis, demonstrated that P57 is concentrated throughout the cortex. In both papers, the unwritten in-house standard $(0.300 \%)$ for P57 content in raw material was questioned. A mere $4 \%$ of all the samples tested attained this "standard", suggesting unrealistic expectations by manufacturers [38].

Microscopy and PCR: Joshi et al. [39] used microscopy and polymerase chain reaction (PCR) to distinguish between different species of Hoodia, the common adulterant 0 . ficus-indica, as well as other related species. Macroscopically and microscopically, Hoodia species could be distinguished from each other as well as all other species. However, in powder form, differentiation between the species of Hoodia was not possible due to the similar physical characteristics of the small particles. The method was able to distinguish between Hoodia species and 0 . ficus-indica which showed oxalate crystals absent in Hoodia species. The mi- croscopic analysis of 15 dietary supplements claiming to contain $H$. gordonii revealed that 6 samples showed the presence of Hoodia species but not $H$. gordonii specifically. Genomic deoxyribonucleic acid (DNA) analysis by PCR was useful to distinguish between different species of Hoodia and 0 . ficus-indica. In addition, the PCR method could distinguish between $H$. gordonii, H. parviflora and $H$. ruschii from dried plant tissue. However, when tablets/capsules were analysed, this method was rendered useless possibly due to degradation of DNA during manufacturing processes. No data is shown on the other related species investigated, but it was mentioned that macroscopically and microscopically, all of these species could be distinguished from Hoodia species [39].

\section{Conclusions}

$\nabla$

Anti-obesity preparations of natural origin are particularly appealing to consumers due to the general perception that if it natural, it must be effective and safe. However, the evidence is to the contrary as seen, for example, in the review by Menniti-Ippolito et al. [30] where 233 spontaneous reports of suspected adverse reactions to natural health products were collected for the period April 2002 to March 2007 in Italy. Two fatal events were recorded, $6 \%$ reported life-threatening clinical events and hospitalisation was required in $35 \%$ of the cases. These alarming statistics confirm the need for essential basic research to be performed before commercialisation of natural products should be allowed. Homoud [31] commented on safety issues in an editorial entitled "The sale of weight-loss supplements on the Internet: A lurking health care crisis waiting to strike". The anti-obesity products freely available on the internet are not well-controlled, if at all, and in many instances these supplements have been implicated in serious health complications and even death. Ma huang (Ephedra sinica), which was banned by the Food and Drug Administration (FDA) in 2004, has been one of the culprits, yet it is still available for purchase on the internet. The occasional use of $H$. gordonii and other Hoodia species as appetite and thirst suppressants by indigenous people is well-documented [13]. However, daily consumption of these Hoodia-containing products in high quantities, such as when used as an anti-obesity preparation, may have important safety implications as toxicity studies investigating this type of consumption have not been performed. The addition of other substances to products (adulteration) is a major problem, and quality control should be considered one of the most important aspects. Traditionally, $H$. gordonii raw material and products have been authenticated and their P57 content quantified with liquid chromatography (LC) methods coupled to a diode array detector (DAD) or mass spectrometer (MS). Several analytical methods have been developed $[9,19,32,33]$, but they are expensive and substantial expertise is needed to perform these analyses. The need for simpler, less expensive, and faster analysis methods gave rise to the use of thin layer chromatography (TLC) and vibrational spectroscopy methods [34-38]. Thin layer chromatography gives visual results, is simple and low in cost; the sample capacity is high and identification as well as qualitative and quantitative results are obtained rapidly [40]. Vibrational spectroscopy, including near-infrared (NIR), mid-infrared (MIR), and Raman, is mostly nondestructive in nature; chemical reagents are not needed, and it provides rapid, simple analysis of samples in any physical form without pretreatment [41]. In the search for a unique characteristic or compound to distinguish 
H. gordonii from other species of Hoodia as well as from adulterants, deoxyribonucleic acid (DNA) testing and macroscopic as well as microscopic examinations have been investigated [39]. However, a compound unique to $H$. gordonii has not been found, and none of the methods developed showed that it could distinguish between different species of Hoodia in powder form used to manufacture products. In addition, all of the quality control studies performed to date showed evidence of fake products claiming to contain H. gordonii. Many of the Hoodia species have been reported to be used for weight loss and contain P57 and other steroidal glycosides, but only $\mathrm{H}$. gordonii has been scientifically investigated to some extent. All pharmacokinetic studies completed up to this point indicated that the oral bioavailability of P57 is low, suggesting that other molecules or metabolites may be responsible for the anti-obesity effect. The aglycone of P57, hoodigogenin $\mathrm{A}$, is a prime candidate for further research. In addition, the investigation of other Hoodia species for anti-obesity activity should be considered. $H$. gordonii seems to be ideally suited for commercial development, but the development has preceded the research phase. Many aspects that should be investigated prior to commercialisation of products claiming biological activity, such as bioavailability of the active ingredient, have been lacking, though recently some of these aspects have been the focus of in vitro and in vivo investigations in animals [26,28, 29]. In addition, several large pharmaceutical companies have withdrawn from development of $H$. gordonii products mostly due to reasons that are unconfirmed and only speculated upon. The San are still hoping to receive royalties out of the benefit sharing agreement, and farmers have mostly set their sights on cultivation of other crops due to a reduction in the price of $H$. gordonii raw material. The Hoodia industry is waning, and they might face an uphill battle to restore public confidence in this product. $H$. gordonii has shown promise to be developed into a pharmaceutical product to be used for the treatment of overweight, but it is evident that further research is needed to validate its worldwide consumption. In addition, the H. gordonii case encompasses all issues related to the development of commercial products from natural origin including intellectual property rights, benefit sharing, and biodiversity issues, protection of natural resources, the complexity of plant extracts, the paramount importance of quality control methods, and the need for proper research including clinical studies prior to commercialisation.

\section{References}

1 Glasl S. Hoodia: A herb used in South African traditional medicine - A potential cure for overweight? Pharmacognostic review of history, composition, health-related claims, scientific evidence and intellectual property rights. Schweiz Z Ganzheitsmed 2009; 21: 300-306

2 World Health Organization (WHO). Fact sheet no 311. Available at: http://www.who.int/mediacentre/factsheets/fs311/en/print.html. September 2006. Accessed September 29, 2009

3 Van Heerden FR, Vleggaar R, Horak RM, Learmonth RA, Maharaj V, Whittal $R D$. Pharmaceutical compositions having appetite-suppressant activity. US Patent 6376657 B1; 2002

4 Pawar RS, Shukla YJ, Khan SI, Avula B, Khan IA. New oxypregnane glycosides from appetite suppressant herbal supplement Hoodia gordonii. Steroids 2007; 72: 524-534

5 Pawar RS, Shukla YJ, Khan IA. New calogenin glycosides from Hoodia gordonii. Steroids 2007; 72: 881-891

6 Dall'Acqua S, Innocenti G. Steroidal glycosides from Hoodia gordonii. Steroids 2007; 72: 559-568

7 Abrahamse SL, Povey KJ, Rees DD. Appetite suppressant compositions. US Patent 0207227 A1; 2007
8 Shukla YJ, Pawar RS, Ding Y, Li X-C, Ferreira D, Khan IA. Pregnane glycosides from Hoodia gordonii. Phytochemistry 2009; 70: 675-683

9 Avula B, Wang YH, Pawar RS, Shukla YJ, Schaneberg B, Khan IA. Determination of the appetite suppressant P57 in Hoodia gordonii plant extracts and dietary supplements by liquid chromatography/electrospray ionization mass spectrometry (LC-MSD-TOF) and LC-UV methods. J AOAC Int 2006; 89: 606-611

10 Van Wyk B-E, Wink M. Medicinal plants of the world. Pretoria: Briza Publications; 2004: 171

11 Bruyns PV. Stapeliads of Southern Africa and Madagascar, Volume 1. Pretoria: Umdaus Press; 2005

12 Olivier I. Hoodia gordonii (Masson) Sweet ex Decne. Available at http:// www.plantzafrica.com/planthij/hoodgord.htm. Accessed February 5, 2008

13 Van Heerden F. Hoodia gordonii: A natural appetite suppressant. J Ethnopharmacol 2008; 119: 434-437

14 Holt S, Taylor TV. Hoodia gordonii: an overview of biological and botanical characteristics: Part 1. Townsend Lett 2006; 280: 104-113

15 Van Wyk B-E, Gericke N. People's plants. Pretoria: Briza Publications; 2000: 70

16 Van Heerden FR, Horak RM, Maharaj VJ, Vleggaar R, Senabe JV, Gunning PJ. An appetite suppressant from Hoodia species. Phytochemistry 2007; 68: 2545-2553

17 Foden W. Information document on trade in Hoodia gordonii and other Hoodia species. Available at http://www.plantzafrica.com/planthij/ hoodia.htm. Accessed June 29, 2010

18 Wynberg $R$, Schroeder D, Chennels $R$. Indigenous peoples, consent and benefit sharing. Lessons from the San-Hoodia case. London: Springer Publications; 2009: 11-26, 89-121

19 Avula B, Wang Y-H, Pawar, RS, Shukla YJ, Smillie TJ, Khan IA. A rapid method for chemical fingerprint analysis of Hoodia species, related genera, and dietary supplements using UPLC-UV-MS. J Pharm Biomed Anal 2008; 48: 722-731

20 Tulp OL, Harbi N. Effect of Hoodia plant on food intake and body weight in lean and obese LA/Ntul//cp-rats. FASEB J 2001; 15: A404

21 Tulp OL, Harbi N. Effect of Hoodia plant on weight loss in congenic obese LA/Ntul//-cp rats. FASEB J 2002; 16: A654

22 MacLean DB, Luo L-G. Increased ATP content/production in the hypothalamus may be a signal for energy-sensing of satiety: studies of the anorectic mechanism of a plant steroidal glycoside. Brain Res 2004; 1020: $1-11$

23 Mohlapo TD, Ng'ambi JW, Norris D, Malatje MM. Effect of Hoodia gordonii meal supplementation at finisher stage on productivity and carcass characteristics of Ross 308 broiler chickens. Trop Anim Health Prod 2009; 41: 1591-1596

24 Holt S, Taylor TV. Hoodia gordonii: Part 2: separating science from speculation. Townsend Lett 2006; 281: 99-104

25 Hakkinen J, Horak RM, Maharaj V. Gastric acid secretion. US Patent $0079233 \mathrm{~A} 1 ; 2005$

26 Madgula VLM, Avula B, Pawar RS, Shukla YJ, Khan IA, Walker LA, Khan SI. Characterization of in vitro pharmacokinetic properties of hoodigogenin A from Hoodia gordonii. Planta Med 2010; 76: 62-69

27 Rubin ID, Bindra JS, Cawthorne MA. Extracts, compounds and pharmaceutical compositions having anti-diabetic activity and their use. US Patent 0159779 A1; 2006

28 Madgula VLM, Avula B, Pawar RS, Shukla YJ, Khan IA, Walker LA, Khan SI. In vitro metabolic stability and intestinal transport of P57AS3 (P57) from Hoodia gordonii and its interaction with drug metabolizing enzymes. Planta Med 2008; 74: 1269-1275

29 Madgula VLM, Ashfaq MK, Wang Y-H, Avula B, Khan IA, Walker LA, Khan SI. Bioavailability, pharmacokinetics, and tissue distribution of the oxypregnane steroidal glycoside P57AS3 (P57) from Hoodia gordonii in mouse model. Planta Med 2010; 76: 1582-1586

30 Menniti-Ippolito F, Mazzanti G, Santuccio C, Moro PA, Calapai G, Firenzuoli F, Valeri A, Raschetti $R$. Surveillance of suspected adverse reactions to natural health products in Italy. Pharmacoepidemiol Drug Saf 2008; 17: 626-635

31 Homoud MK. The sale of weight-loss supplements on the Internet: A lurking health crisis waiting to strike. Heart Rhythm 2009; 6: 658-662

32 Janssen H-G, Swindells C, Gunning P, Wang W, Grün C, Mahabir K, Maharaj VJ, Apps PJ. Quantification of appetite suppressing steroid glycosides from Hoodia gordonii in dried plant material, purified extracts and food products using HPLC-UV and HPLC-MS methods. Anal Chim Acta 2008; 617: 200-207 
33 Avula B, Wang YH, Pawar RS, Shukla YJ, Khan IA. Chemical fingerprinting of Hoodia species and related genera: chemical analysis of oxypregnane glycosides using high-performance liquid chromatography with UV detection in Hoodia gordonii. J AOAC Int 2007; 90: 1526-1531

34 Widmer V, Reich E, DeBatt A. Validated HPTLC method for identification of Hoodia gordonii. J Planar Chromatogr Mod TLC 2008; 21: 21-26

35 Rumalla CS, Avula B, Shukla YJ, Wang Y-H, Pawar RS, Smillie TJ, Khan IA. Chemical fingerprint of Hoodia species, dietary supplements, and related genera by using HPTLC. J Sep Sci 2008; 31: 3959-3964

36 Vermaak I, Hamman JH, Viljoen AM. High performance thin layer chromatography as a method to authenticate Hoodia gordonii raw material and products. S Afr J Bot 2010; 76: 119-124

37 Vermaak I, Hamman JH, Viljoen AM. A rapid spectroscopic method for quantification of P57 in Hoodia gordonii raw material. Food Chem 2010; 120: 940-944
38 Vermaak I, Viljoen AM, Hamman JH, Baranska M. The potential application of FT-Raman spectroscopy for the quantification and mapping of the steroidal glycoside P57 in Hoodia gordonii. Phytochem Lett 2010; 3: $156-160$

39 Joshi V, Techen N, Scheffler BE, Khan IA. Identification and differentiation between Hoodia gordonii (Masson) Sweet ex Decne., Opuntia ficus indica (L.) P. Miller, and related Hoodia species using microscopy and PCR. J Herbs Spices Med Plants 2009; 15: 253-264

40 Marston A. Role of advances in chromatographic techniques in phytochemistry. Phytochemistry 2007; 68: 2785-2797

41 Moros J, Garrigues S, De la Guardia M. Vibrational spectroscopy provides a green tool for multi-component analysis. Trends Anal Chem 2010; 29: 578-591 